Article

\title{
Development of Final Projects in Engineering Degrees around an Industry 4.0-Oriented Flexible Manufacturing System: Preliminary Outcomes and Some Initial Considerations
}

\author{
Isaías González *(i) and Antonio José Calderón $(D)$ \\ Department of Electrical Engineering, Electronics and Automation, University of Extremadura, \\ Avenida de Elvas, s/n, 06006 Badajoz, Spain; ajcalde@unex.es \\ * Correspondence: igonzp@unex.es; Tel.: +34-924-289-600
}

Received: 8 October 2018; Accepted: 4 December 2018; Published: 9 December 2018

check for updates

\begin{abstract}
New paradigms such as the Industry 4.0, the Industrial Internet of Things (IIoT), or industrial cyber-physical systems (ICPSs) have been impacting the manufacturing environment in recent years. Nevertheless, these challenging concepts are also being faced from the educational field: Engineering students must acquire knowledge and skills under the view of these frameworks. This paper describes the utilization of an Industry 4.0-oriented flexible manufacturing system (FMS) as an educational tool to develop final projects (FPs) of engineering degrees. A number of scopes are covered by an FMS, such as automation, supervision, instrumentation, communications, and robotics. The utilization of an FMS with educational purposes started in the academic year 2011-2012 and still remains active. Here, the most illustrative FPs are expounded, and successful academic outcomes are reported. In addition, a set of initial considerations based on the experience acquired by the FP tutors is provided.
\end{abstract}

Keywords: engineering education; flexible manufacturing system; Industry 4.0; final project; automation; supervision; robotics; industrial communications

\section{Introduction}

Manufacturing systems are experiencing the advent of innovative trends brought by the information and communication technologies (ICTs)-enabled digital transformation. New paradigms like Industry 4.0, the Industrial Internet of Things (IIoT), industrial cyber-physical systems (ICPSs), or cloud manufacturing (CM) are the most impactful approaches that have arrived to stay. Indeed, Industry 4.0, the so-called fourth industrial revolution, is based on the wide adoption of the IIoT and ICPSs [1]. The next generation of factories are conceived as smart environments where machines, sensors, and actuators are interconnected to enable collaboration, monitoring, and control [2]. As asserted by Cohen et al. [3], one of the reasons for the fascination of Industry 4.0 is that it is an industrial revolution predicted a priori, which provides various opportunities for companies and research institutes to actively shape the future. The implications of Industry 4.0 and associated technologies reach all types of factories, from small and medium-sized enterprises [4] to broader industries such as chemical manufacturing [5] or oil and gas processing [6].

A number of challenges need to be solved for the real implementation of the Industry 4.0-compliant systems: Networked connection of components, massive data gathering, interoperability handling, a wide adoption of ICTs, high investments, collaborative robotics, cyber-security issues, and enhanced flexibility, just to name a few [7]. 
Another paramount aspect of Industry 4.0 is its impact on employment. There is an unsolved debate about the increase or decrease of employee numbers as a consequence of Industry 4.0 [8]. What seems to be clear is that diverse job profiles are required, such as automation programmer, robot programmer, informatics specialists, software engineer, data analyst, and cyber security specialist [9]. Only qualified and highly educated employees will be able to control these technologies [9]. In this sense, well-prepared Industry 4.0 engineers need an interdisciplinary understanding of systems, production processes, automation technology, information technology, and business processes [10].

Consequently, education and training play an essential role for successful Industry 4.0 implementation. Contents and skills provided to engineering students must encompass the challenging growth of technological advancement [7]. In other words, universities have to provide students with the ability to manage new trends for effective future professional development [7]. In fact, in engineering degrees this concept is raising an increasing interest from educators, as demonstrated by recent examples where courses scheduling and laboratory designs were conducted taking into account the Industry 4.0 framework [10-13]. Indeed, terms like "engineering education 4.0" or "engineer 4.0" are appearing in the literature [14].

Moreover, not only do higher education institutions have to make efforts in this direction, but industrial manufacturing enterprises have to provide specific training and learning solutions for their employees, especially for engineers, technicians, and operational workers. In this sense, companies must pay attention also to Industry 4.0 education-oriented new approaches.

In general, from an educational perspective, it is mandatory for the utilization of experimental systems to apply theoretical concepts and acquire practical skills. Operation of real devices and tools that future engineers will handle in their professional path constitutes a necessity for students $[15,16]$. Even more, the higher the level of fidelity and realism, the better learning and training are achieved [17]. Therefore, experimental advanced Industry 4.0-compliant equipment is required to act as a didactic platform for successful learning outcomes. A versatile framework that fulfills the abovementioned requisites is a flexible manufacturing system (FMS). An FMS is a flexible automation facility composed by a set of work stations that perform operations over a product that is being processed. The product is transported using a conveyor or transfer around which stations are deployed, acting as a backbone. A number of control units, sensors and actuators, and supervisory interfaces share information in real time through a communication network. FMS has a modular architecture that allows for reorganizing the work stations for different processes and operations [18]. Other terms are also applied for similar or equal concepts: Flexible manufacturing cell, reconfigurable manufacturing system, reconfigurable assembly system, or modular production system. These types of systems are part of the Industry 4.0 environment due to the fact that they are modular manufacturing systems characterized by integrated sensors and standardized interfaces, which corresponds to the enabling technology of Industry 4.0 [19].

An FMS involves a great amount of technology in an integrated manner. Therefore, Figure 1 is expected to show the versatility of an FMS in being used for Research and Development (R\&D) and educational activities. In this sense, diverse scopes can be worked: Supervisory systems, automation, networked communications, instrumentation, production scheduling, interoperability handling, maintenance, robotics, and intelligent control, just to name a few, can be trained through an FMS. 


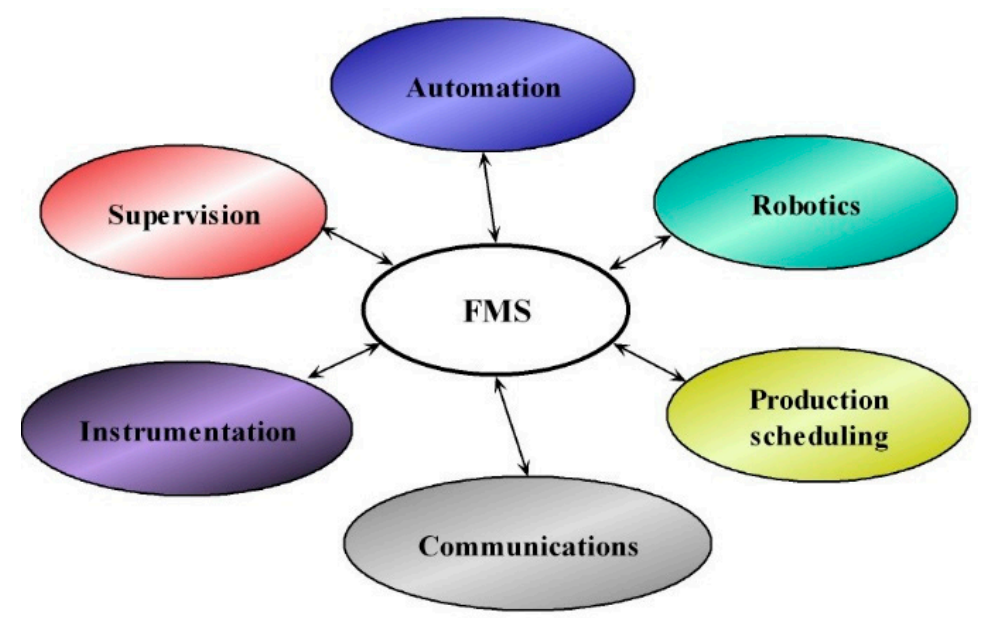

Figure 1. Scopes that can be trained through a flexible manufacturing system (FMS).

In scientific literature, FMSs are profusely used for R\&D tasks, for instance in the context of production scheduling [20-23], for integration of the low-cost open source platform Arduino [24], or for applying an Industry 4.0-compliant architecture [25]. An extensive review about applications of FMS can be found in Reference [19].

However, there is a serious scarcity of works dealing with educational approaches that contribute to train the personnel (both engineers and operators) that have to handle such advanced systems. Some recent examples about the utilization of FMS as an educational tool will now be expounded. In the University of León, a FMS has been fully developed and used as a remotely accessible laboratory [26]. Reynard et al. [27] have proposed the educational utilization of a Supervisory Control and Data Acquisition (SCADA) system devoted to an FMS. A didactic FMS and a supervisory system based on LabVIEW were presented in Reference [28]. Various scenarios combining real and virtual processes and controllers by means of an FMS were developed in Reference [29] and were used as an educative environment within a mechatronic laboratory. Toivonen et al. [30] have remarked on the versatility of FMS for engineering education, reporting possible pedagogical applications involving a digital twin of the system. In Reference [31], a group of students performed activities over a full-size didactic FMS in order to evaluate a human-machine cooperation approach toward future manufacturing processes in the Industry 4.0 scenario. Recently, modular manufacturing stations and FMSs have been used as essential parts of Industry 4.0-oriented educational laboratory facilities [10,12]. Learning factory (LF) is also a related concept that in general comprises complex facilities that mimic real production processes and environments, and it is used to develop competencies for present and future personnel [32]. These facilities play a key role in linking academia to industry to spread the culture of innovation [19]. In the present case, the educational-oriented usage of an FMS is simpler, but aims to constitute an initial approximation to such an environment.

The present work reports the utilization of an FMS as a didactic environment to support the development of final projects (FPs) for engineering degrees. An FMS and the most representative FPs are briefly described to provide a perspective of its functionalities and educational capabilities. The FPs were devoted to tasks mainly related to automation, supervision, robotics, and data retrieving. Nonetheless, other important skills can be trained, such as communications, systems integration, sensors and actuators, as will be expounded. Experience accumulated during seven years in the utilization of a real FMS is reported. The successfully achieved academic outcomes are analyzed. The goal of the paper is to provide some early considerations from the perspective of the tutors based on the abovementioned experience.

FMSs are described in the theoretical sessions of courses as a complex and advanced system derived from the evolution of industrial automation equipment. This occurs in a variety of courses, not only in those specifically centered around industrial automation, but in robotics, supervisory 
systems, and other courses. However, the physical availability of laboratory-scale real industrial FMS equipment is scarce. The main reason is that acquiring an FMS requires a big investment. In fact, the motivation for this paper arose when trying to take advantage of an FMS acquired in the context of an R\&D project in collaboration with a manufacturing enterprise. Once the project finished, such valuable equipment was available to be used also for academic activities. Apart from a continuation of the resource utilization, this provided valuable opportunities to teach advanced systems to students, instead of didactic plants. The authors saw the enormous educational potential and decided to offer the opportunity of managing the system under the FP concept. In fact, an FMS is suitable for accommodating different technological approaches as well as pedagogical methodologies.

This paper aims to contribute to fostering a realistic educational environment for automationrelated students, mainly oriented to Industry 4.0. Educators can find useful ideas to implement didactic approaches toward an in-depth acquisition of skills for future engineers. Even the information can be used to schedule training sessions for practitioners or workers in manufacturing enterprises.

The remainder of the rest of the paper is as follows. Section 2 deals with organizational aspects of the FPs to give a contextualization of the FMS-based FPs. In Section 3, a description of an FMS is provided jointly with the most demonstrative FPs. In Section 4, the main educational outcomes of the FPs in terms of devoted time, achieved marks, and covered scope are expounded, as well as initial considerations from the educators. Finally, the main conclusions of the work are provided in the last section.

\section{FP Procedure}

This section aims to provide a brief contextualization of the FPs in the Industrial Engineering School (IES) at the University of Extremadura (UEX) by indicating the main norms and processes involved.

The European Higher Education Area (EHEA) has involved a structural reorganization as well as a shift of the paradigm in universities, emphasizing the relevance of students and the development of skills. Furthermore, at the same time, the global crisis reached academic institutions, reducing the financial resources for acquisition and maintenance of didactic equipment devoted to laboratories.

The IES of the UEX, placed in the city of Badajoz, was founded in 1975, and started the adaptation to the EHEA in the academic year 2009/2010. Nowadays, a total amount of 120 teachers and an average number of 1200 students characterize the school [33].

A paramount part of the engineering degrees is the final project (FP), also called a final year dissertation or a bachelor's or master's thesis, which students have to complete as a final stage prior to achieving their engineer title. The FP consists of an autonomous project developed by the student under the supervision of a tutor. It is intended to reinforce the skills achieved during the degree or to acquire new complementary skills related to their specialization.

The EHEA brought an important novelty regarding FPs, the obligatory development of an FP for every degree. Nonetheless, this was not an authentic novelty for engineering since FPs were already required to finish the degree since its origin. Nowadays, FPs have a duration of 12 European credits, which are equivalent to $300 \mathrm{~h}$, for bachelor's and master's degrees. It is considered to be a course, so it is scheduled in the last semester of the degree. In fact, it has to be presented once the rest of courses have been passed. Note that the bachelor's degree has a duration of four years, whereas the master's degrees last two years. All the norms about FPs and associated documents are publicly available on the webpage of the IES so students can easily find online the information regardless of their particular situation (e.g., academic year, specialization).

The block diagram depicted in Figure 2 shows the stages that must be completed for FP development, from the FP topic definition up to the dissertation event. 


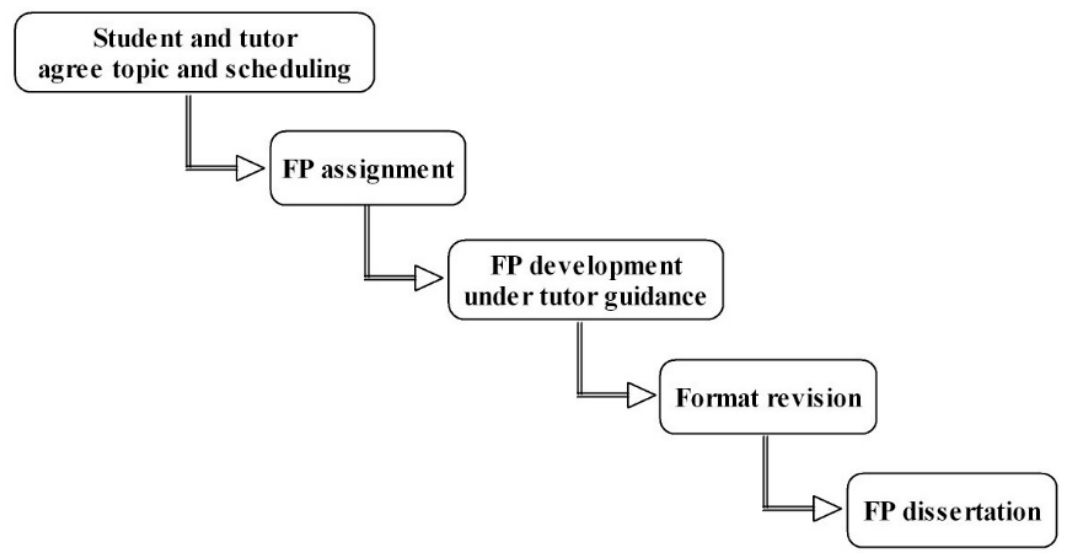

Figure 2. Block diagram of final project (FP) development over time.

As can be observed, the first step consists of selecting or agreeing on the topic. It can be proposed by the student and arranged with the teacher, or delivered from the department offer. Once established, the FP assignment implies the formal compromise of the student, the tutor, and the topic during an academic year.

Each FP can be supervised by one or two tutors belonging to the IES staff. At least one of them must be a teacher of a knowledge area with teaching in the degree of the student. The guidance process of each FP is worth 0.25 European credits for the tutor. Another issue agreed between the tutor and the student consists of the envisioned duration of the FP. Different factors are taken into account such as pending courses and the motivations of the student. In addition, once the project has started, deviations can occur due to a variety of reasons, such as unexpected technical difficulties or learning rhythm variations. In such cases, the tutor establishes a new temporization adapted to the current situation.

The student is supposed to write the project report progressively, during the whole process of the FP. The final document must encompass a series of format rules, so a teacher is designated to revise such issues as a requirement previous to the dissertation. This step is named the "Format revision" in Figure 2.

The dissertation procedure in this university consists of a public event divided into a student-driven exposition and a rigorous argumentation with the tribunal. This tribunal is composed of three professors, responsible for assessing the FP. It must be noted that the tutor does not belong to the assessment tribunal. Figure 3 aims to illustrate the dissertation procedure. Its public nature facilitates the assistance of the student's parents, family, and friends, and also of other FP students aiming to learn about the event. The expected duration is around $30 \mathrm{~min}$.

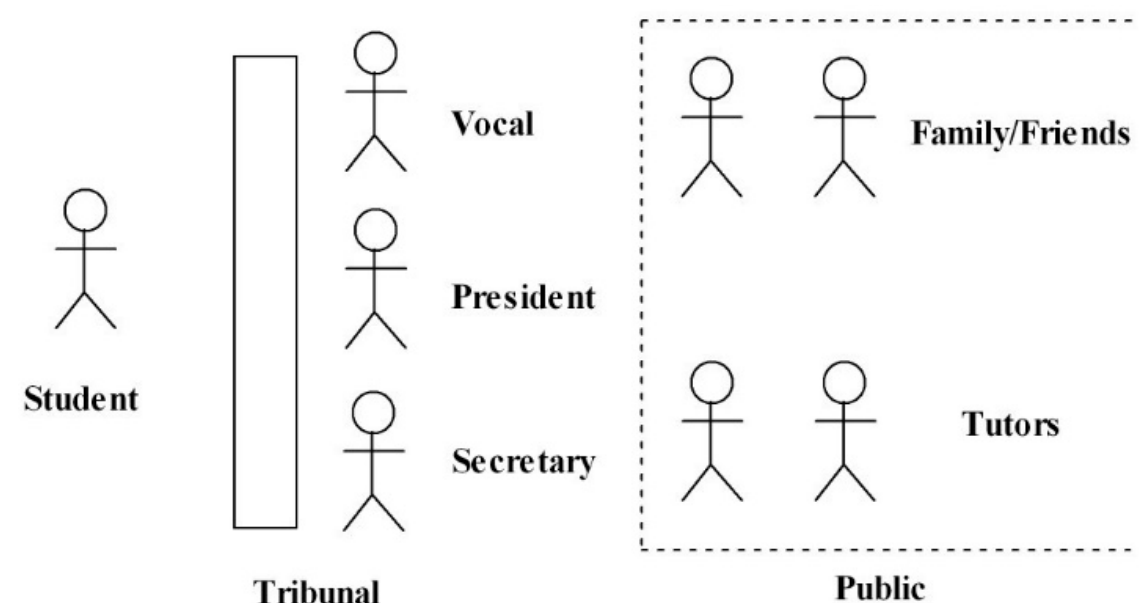

Figure 3. Illustration of the dissertation procedure. 
To establish the associated final mark (FM), two rubrics are used by the tribunal in the IES. On the one hand, there is a rubric devoted to assess the project report, report mark (RM), whose weight is $70 \%$ of the FM. On the other hand, the dissertation process receives a mark according to another rubric, called the dissertation mark (DM). Consequently, the FM is obtained according to this equation:

$$
\mathrm{FM}=0.7 \times \mathrm{RM}+0.3 \times \mathrm{DM} .
$$

The achievable mark is between 0 and 10, and a distinction award can be reached if the FP receives a mark of 10 and other academic merits have been met. The assessment of this latter consideration is made outside of the tribunal faculties.

For a better comprehension of the students' training in automation and complementary disciplines, Table 1 collects the courses classified into the corresponding degree or master. A noticeable remark is that the Bachelor's Degree in Electronic Engineering and Automation is the most aligned with FMS resources. However, any other degree or master's can be accommodated in such a system. In fact, as aforesaid, one of the advantages and goals of the FPs is to allow students to acquire expertise in fields that have not been deeply studied in previous courses. In the same sense, it must be noted that up to the present date, only FPs for degrees have been carried out, but an FMS is suitable for a PhD thesis.

Table 1. Previous and complementary courses related to automation and supervision.

\begin{tabular}{|c|c|c|}
\hline Title & Course & Character \\
\hline $\begin{array}{c}\text { Bachelor's Degree in Electronic Engineering } \\
\text { and Automation }\end{array}$ & $\begin{array}{c}\text { Introduction to Automation } \\
\text { Automation I } \\
\text { Automation II } \\
\text { Industrial Process Control } \\
\text { Robotics and Perception Systems } \\
\text { Supervisory Control Systems }\end{array}$ & $\begin{array}{l}\text { Obligatory } \\
\text { Obligatory } \\
\text { Obligatory } \\
\text { Obligatory } \\
\text { Obligatory } \\
\text { Optional }\end{array}$ \\
\hline Bachelor's Degree in Electrical Engineering & $\begin{array}{l}\text { Introduction to Automation } \\
\text { Industrial Automation } \\
\text { Supervisory Systems }\end{array}$ & $\begin{array}{c}\text { Obligatory } \\
\text { Obligatory } \\
\text { Optional }\end{array}$ \\
\hline Bachelor's Degree in Mechanical Engineering & $\begin{array}{l}\text { Introduction to Automation } \\
\text { Industrial Automation }\end{array}$ & $\begin{array}{l}\text { Obligatory } \\
\text { Optional }\end{array}$ \\
\hline $\begin{array}{l}\text { Bachelor's Degree in Industrial } \\
\text { Chemical Engineering }\end{array}$ & $\begin{array}{c}\text { Electronic Engineering and Automation } \\
\text { Process Engineering II }\end{array}$ & $\begin{array}{l}\text { Obligatory } \\
\text { Obligatory }\end{array}$ \\
\hline Master's Degree in Industrial Engineering & $\begin{array}{l}\text { Electronic Technology and Automation } \\
\text { Automation of Production Systems }\end{array}$ & $\begin{array}{c}\text { Obligatory } \\
\text { Optional }\end{array}$ \\
\hline $\begin{array}{c}\text { Master's Degree in Research in Engineering } \\
\text { and Architecture }\end{array}$ & $\begin{array}{c}\text { Introduction to Research in Advanced } \\
\text { Automation Techniques }\end{array}$ & Optional \\
\hline
\end{tabular}

Apart from FPs dealing with FMSs that are expounded in the present paper, the authors also tutor projects about industrial automation and supervision, automated renewable energy systems, and open source devices for data acquisition and automatic control. Some details about the guidance procedure particularly followed by the authors are now commented on. An example of ICT utilization within the presented approach consists of using a Moodle-based learning management system (LMS) for tracking the projects' development. This virtual space is shared between the educators and the students, not only devoted to FMS-based FPs. Tutors upload documents and web links so students can find them easily online. Such information covers aspects related to common procedures about FPs such as norms and advice (about writing the report or the dissertation), as well as meeting requirements. A bidirectional flow of information is established, since both teachers and students can talk through the available forum in the Moodle-LMS, facilitating asynchronous communication and giving students the opportunity for active communication, even among them. Group meetings are carried out mainly 
in the initial stage of FPs in order to give common information to students regardless of the specific topic. The contents are mainly focused on scheduling aspects of the FPs and on the proposed means of student-tutor communication.

\section{FMS and FPs Description}

Now that the FP contextualization has been provided, in this section the FMS around which the projects were developed is briefly described. Likewise, in the second subsection, in order to provide an overview of the educational capabilities of an FMS in the Industry 4.0-related field, the most illustrative FPs are explained.

\subsection{FMS Description}

The utilized FMS is manufactured by the company SMC (Tokyo, Japan) [34]. It accomplishes the assembly and storage of a turning mechanism composed of the following elements: Body, bearing, shaft, cap, and screws. The set is transported in a pallet over the conveyor belt or transfer that acts as a backbone linking the different stations. To complete the assembly, the whole system consists of eight stations. However, currently the FMS is implemented with four stations, those numbered as 1,7 , and 8 , and an empty station that is being equipped. Each station has a table-like structure where the components are mounted, such as robots, pneumatic cylinders and distributors, motors, and sensors [18]. In addition, each station is automated by a programmable logic controller (PLC), and all of them are integrated into a fieldbus Process Fieldbus (PROFIBUS) in order to exchange operational information such as sensor signals or control commands.

Concerning the function of the stations, the so-called station 1 (S1) supplies the body and checks its correct position. The next station is the number 7 (S7), which consists of a robotized screwing through an industrial robot arm of the manufacturer ABB (Zürich, Switzerland). Station 8 (S8) implements an automatic warehouse by means of a 2D Cartesian robot. As aforementioned, the last station is nowadays being equipped, namely with a 3D Cartesian robot. Finally, a modular transfer composed of conveyor belts enables the joint operation of all the stations. Over this transfer, the pallets transport the set of pieces between stations. A block diagram of the FMS is depicted in Figure 4 to portray the layout of the stations. As can be observed, the four stations are deployed to achieve a closed square circuit, allowing a continuous and cyclic execution.

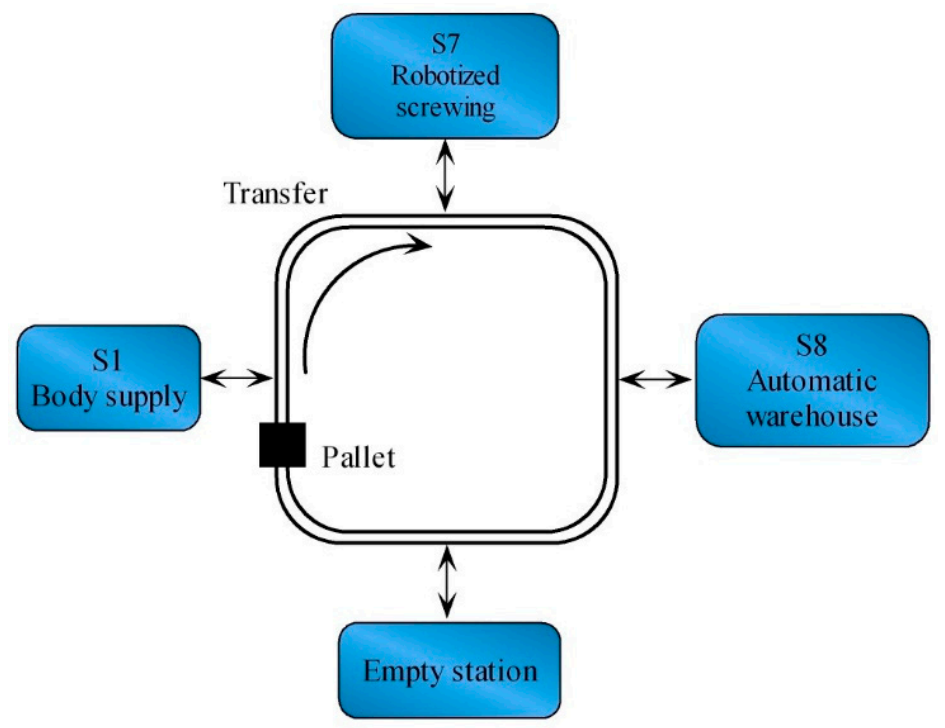

Figure 4. Block diagram of the FMS showing the deployment of the stations. 
An assembled turning mechanism mounted over a transport pallet is appreciable in Figure 5a. The whole FMS in the laboratory is shown in Figure 5b. Further details about the FMS can be found in Reference [18].

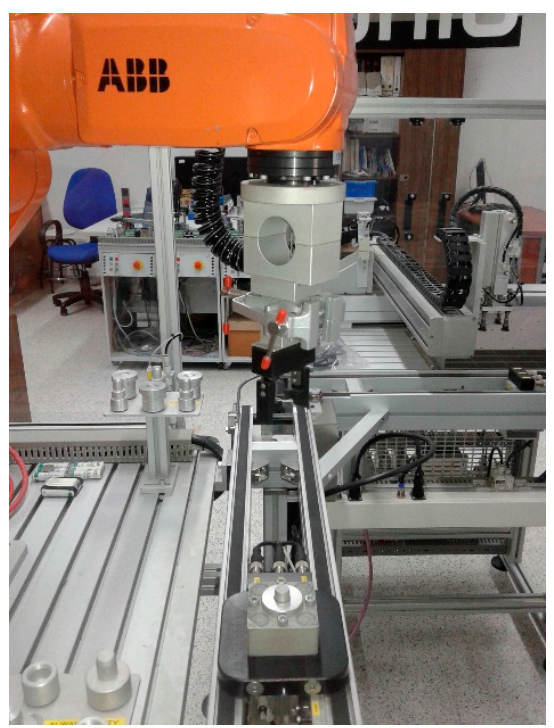

(a)

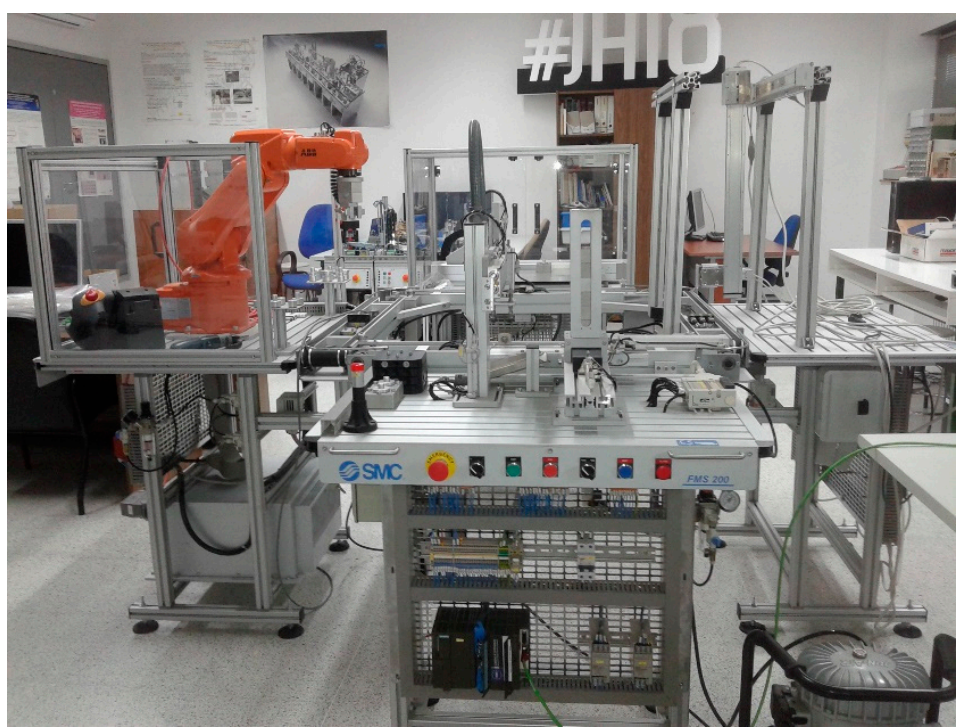

(b)

Figure 5. Aspects of the experimental components: (a) Assembled turning mechanism over a pallet; (b) complete FMS.

Apart from the description of the FMS, at this point it is appropriate to explain diverse security considerations that have been taken into account during the projects' development aiming to reduce potential risks both for students and for the equipment. Damage can be caused by physical reasons, unwanted users, or electrical discharges. Table 2 enumerates the security means that have been implemented classified according to the type of risk.

Table 2. Risks and the associated security means.

\begin{tabular}{cc}
\hline Risk & Security Means \\
\hline Electrical & Electrical protections against discharges \\
Physical & Physical barriers surrounding the FMS; emergency buttons; limited access to the laboratory \\
Software & Boundaries in programmable logic controller (PLC) code; user authentication for supervisory management \\
Cyber threats & Isolation of the local area network (LAN) devoted to FMS-related communications \\
\hline
\end{tabular}

\subsection{Illustrative FPS}

Among the 12 FPs that have been carried out using the FMS, four of them are now concisely described to illustrate the scope that has been fruitfully covered.

\subsubsection{First-Step Project: Automation of the First Version of the FMS}

In this FP, the different stations that composed the initial FMS were integrated from a logical point of view. On the one hand, the fieldbus PROFIBUS was used to interconnect the PLCs of the stations as well as sensors and actuators, and on the other hand, the coordination of the automatic operation was programmed in those PLCs to achieve proper behavior of the FMS. The software STEP7 of the TIA Portal environment was utilized to configure and parameterize the system. The definition of the automation network architecture in such software is seen in Figure 6. It must be noted that in the initial stage of the FMS, only three stations were available. The fourth station (the empty one) was acquired some years later and added to the FMS through another FP. 


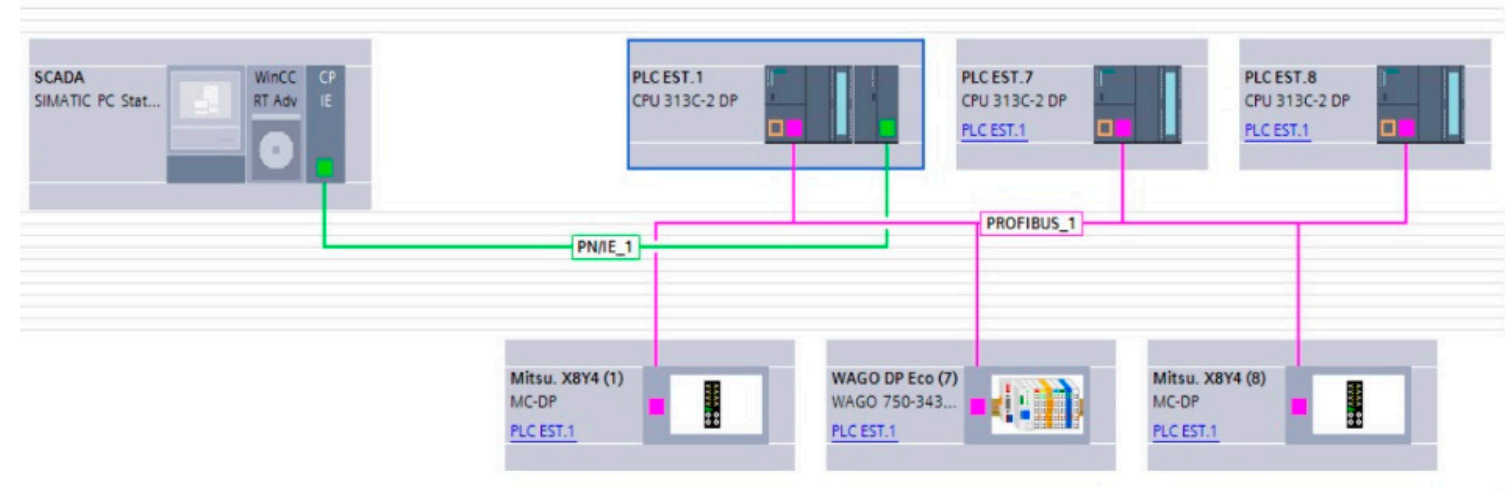

Figure 6. Definition of the automation network architecture for the FMS.

\subsubsection{Supervisory Control and Data Acquisition (SCADA) System Development}

In this FP, a supervisory system was designed and implemented in order to monitor and manipulate all the elements that composed the FMS. The package WinCC of the suite TIA Portal of Siemens was used for this purpose. The runtime application runs in a PC that is connected to the master PLC of the FMS with the goal of exchanging all the data. Such a connection was implemented via Industrial Ethernet (IE) in order to meet the standard means of communication in Industry 4.0 [18]. An intuitive and user-friendly interface was designed in order to illustrate the status and behavior of the FMS. Two sample screens of the SCADA system are shown in Figure 6. The interface devoted to visualizing the operation of the S7 is seen in Figure 7a, and the screen for monitoring the S8 corresponds to Figure $7 \mathrm{~b}$. It should be noted that this FP and the previous one were developed by two students simultaneously and coordinately in order to accomplish the FMS in an effective manner.

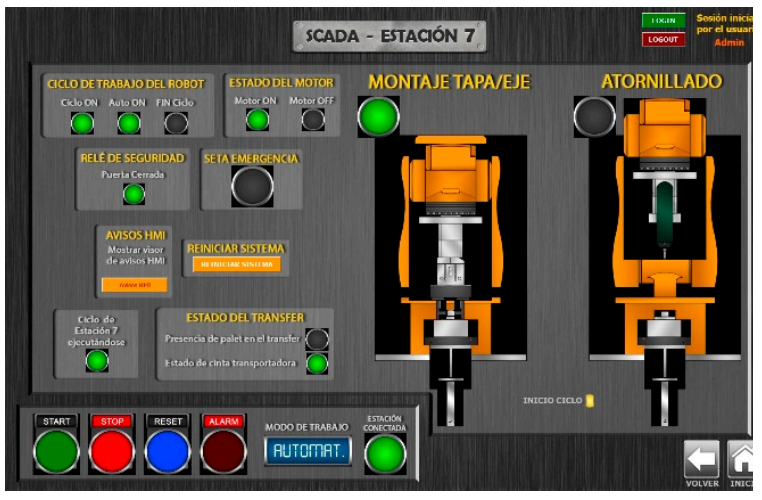

(a)

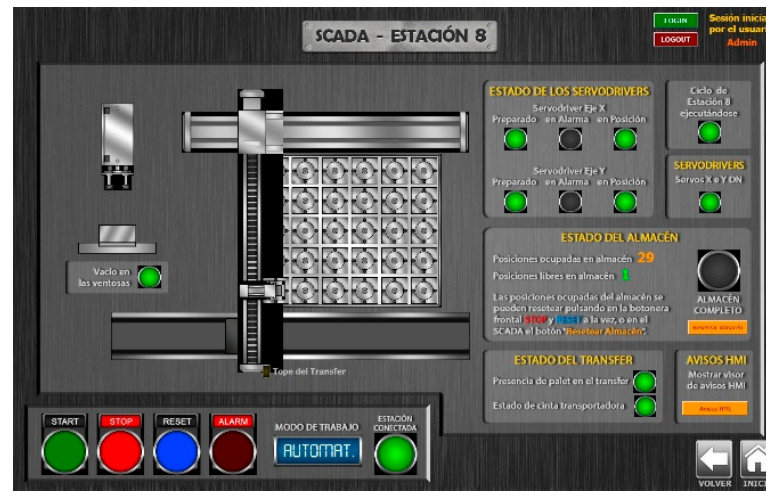

(b)

Figure 7. Screens of the supervisory control and data acquisition (SCADA) system developed in a FP: (a) Screen to monitor the operation of the S7; (b) screen to monitor the operation of the S8.

\subsubsection{Data Storage in a Database}

Within industrial utilization of manufacturing systems, the proper storage and treatment of information plays a vital role both for an effective operation and for higher hierarchical levels that manage software applications such as enterprise resource planning (ERP) or manufacturing execution systems (MESes). Under this perspective, in this FP a data storage mechanism was implemented for the signals handled in the FMS. Structured query language (SQL) reports were generated to record information in an in-house database, which is an accessible data source for other applications. Within the SCADA system, a set of scripts coded in Visual Basic (VB) are responsible for launching the data recording task. In Figure $8 \mathrm{a}$ the deployment of the database is schematized through a block diagram, whereas in Figure 8b a part of the designed VB code is shown. 


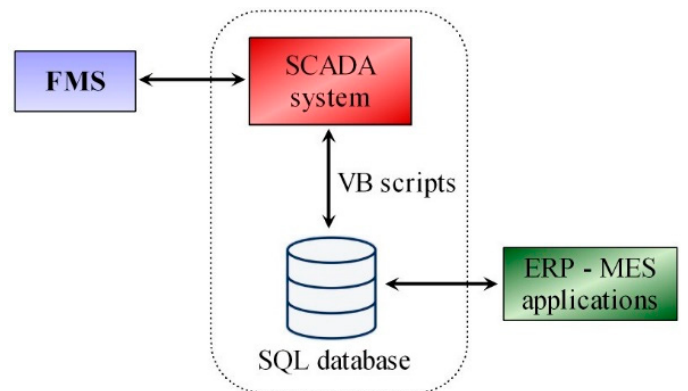

(a)

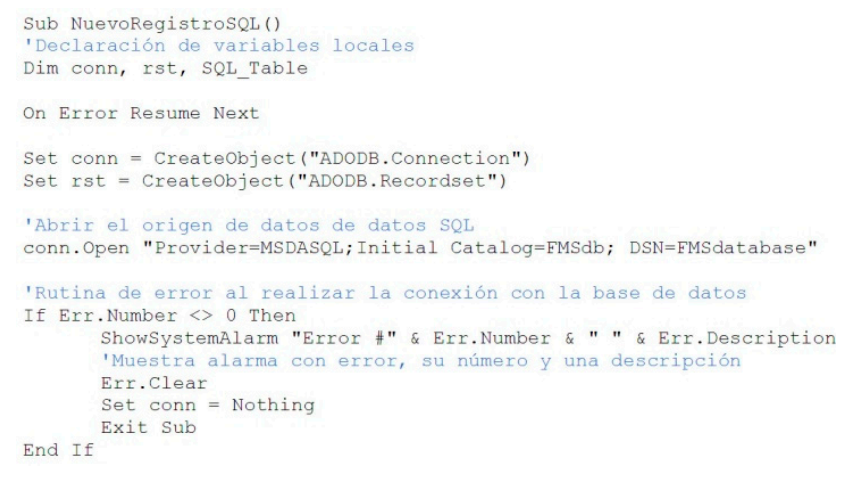

(b)

Figure 8. Deployment of a database for the FMS: (a) Block diagram of the approach; (b) details of the code of a Visual Basic (VB) script.

\subsubsection{Anthropomorphic Robot Arm Programming}

The programming of a robotic arm was carried out in this project. The trajectory that the robot performed was defined in robotics application programming interactive dialogue (RAPID) language, so the students could modify it in order to execute different tasks. For instance, one of the FPs devoted to robotics consisted of programming the tracking of a triangular surface and also the drawing of some geometric shapes. ABB Robot Studio software was used both for the simulation and definition of the new trajectories. In Figure 9a, an image of the 3D representation of a robotic arm following a triangular surface can be observed. A star drawing traced by the robot can be seen in Figure $9 \mathrm{~b}$.

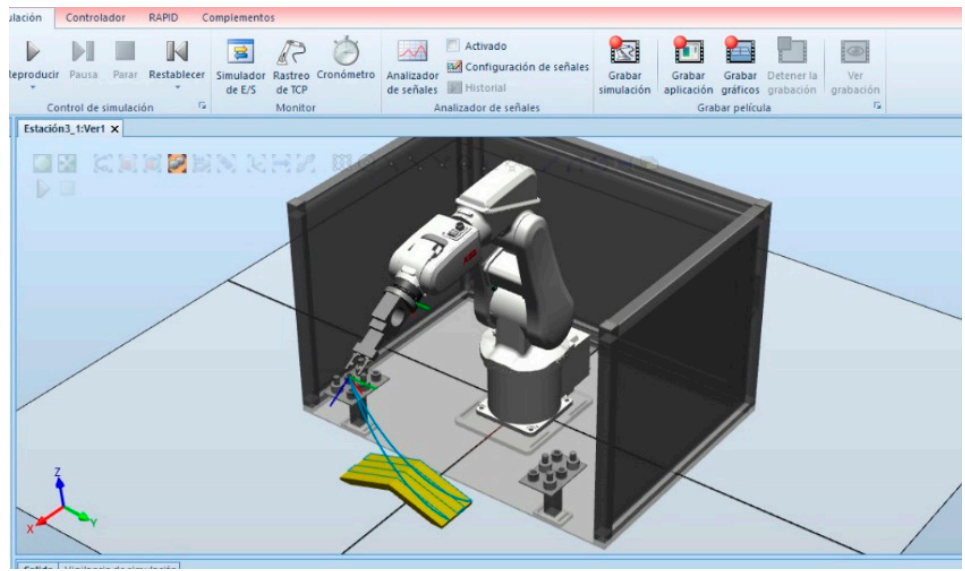

(a)

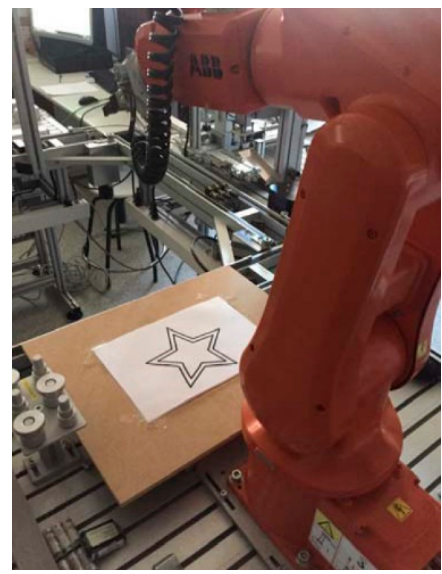

(b)

Figure 9. Aspect of the tasks developed in a robotics-devoted FP: (a) Screenshot of the ABB Robot Studio software used to program a surface tracking application; (b) photograph of a drawing performed by the robotic arm.

Apart from utilization in the FP context, the FMS constitutes a useful resource for different didactic tasks. For instance, in order to attract future students, the university organizes guided visits for high school students during the month of March. Within the engineering laboratories, the FMS is shown to those students, since it provides attractive insights into the spheres of automation and robotics. Indeed, the FMS performs a working cycle to demonstrate the integration of the stations, since the anthropomorphic robot is the most eye-catching element according to the impressions expressed by the students. In a similar way, this system is presented to students of optional courses devoted to supervisory systems as an example of a real and advanced environment where the concepts and skills that they are learning can be applied. 


\section{Discussion}

The development of the above-described FPs has given rise to a powerful benchmark where students, and even also teachers, can learn about advanced automation, supervision, systems integration, industrial network communications, sensors and actuators, robotics, and so forth. This multidisciplinary skills support is a key feature of the FMS, which makes it suitable to be utilized as an experimental benchmark under the Industry 4.0 focus. The discussion conducted in this section is divided into three parts. The first one is dedicated to describing the educational outcomes of the FPs through these parameters: Devoted time, achieved mark, and covered scope. The second subsection reports the considerations from the tutors' perspectives, covering both advantages and disadvantages. Finally, emerging trends in manufacturing and automation that can be trained in the FMS are commented on.

\subsection{Academic Outcomes}

The obtained marks have been very good in every FP, as can be observed in Figure 10, where the number of developed FPs and their corresponding mean marks and devoted months from academic year 2011-12 up to the present date are shown. It should be clarified that the spent time was considered from the real start of the project, not from the assignment document.

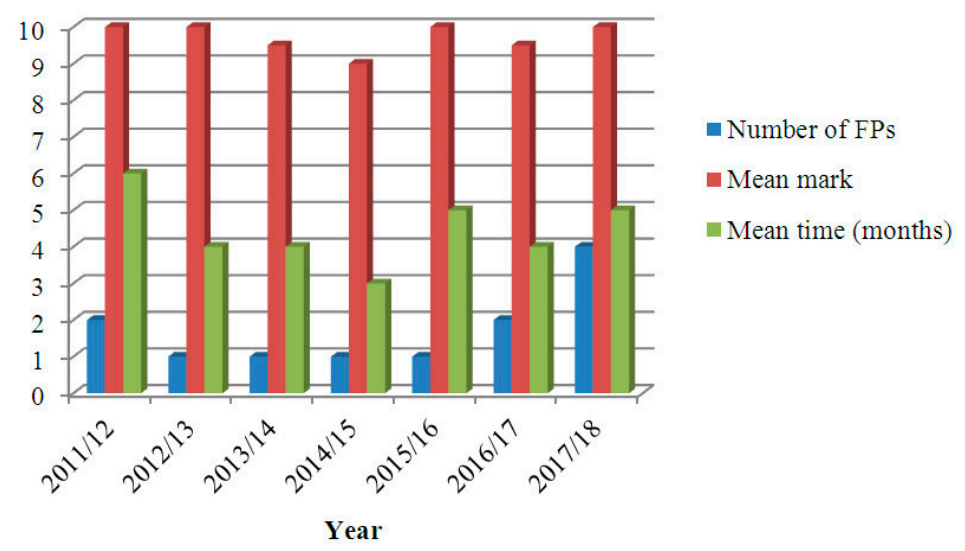

Figure 10. Number of developed FPs and their corresponding mean marks and devoted months.

The mean time devoted to developing the projects was around 4.5 months. The FP course FP is supposed to last a semester (i.e., 12 credits), as explained in the second section. However, as it is well known, the FP is commonly performed in the last stage of the degree. Therefore, the devoted time is very variable depending on the particular situation and motivation of the students.

Concerning the number of FPs, it must be noted that in the recently finished academic year, four projects were performed, which is the largest amount to date. At the present moment, two FPs are being started in the FMS, but they have not been considered for the manuscript.

The development of FPs supported by the FMS is feasible according to the described academic outcomes. This advanced facility has promoted the introduction of the Industry 4.0 paradigm in engineering degrees. In addition, apart from the four reported projects, another eight have been carried out using the FMS. Most of them were devoted to programming the Cartesian and anthropomorphic robots. For instance, the last two FPs were devoted to designing and automating a 3D Cartesian robot in the empty station. Figure 11 illustrates the classification of the FPs according to their main scope. In other words, every project has involved all the scopes at a higher or lower level, but in order to provide insight into the capabilities of the FMS, they have been classified taking into account the principal goal. As can be observed, those devoted to automation and robotics were prevalent, four FPs for each scope. This is coherent with the fact that most students have passed a course entitled "Automation II" where both topics are the core of this course. 


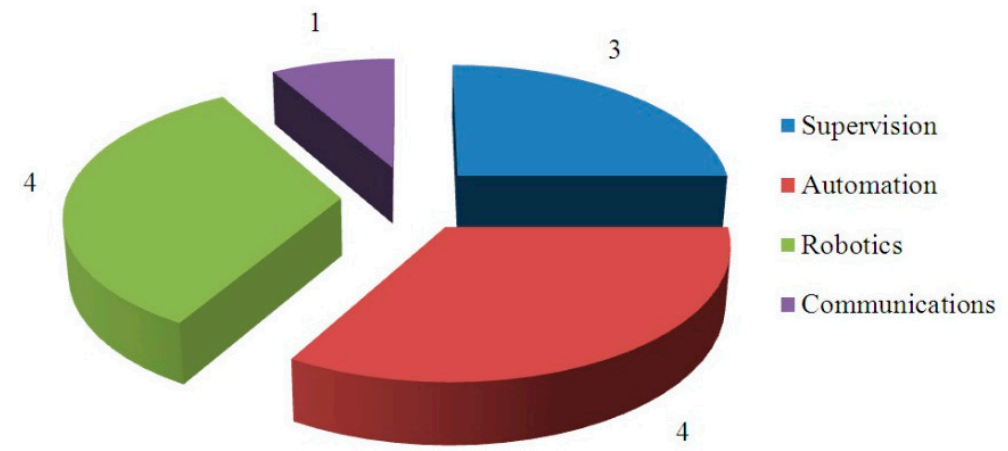

Figure 11. Classification of developed FPs regarding their main scope.

With the goal of illustrating the different elements with which students have been training, Table 3 enumerates such elements divided into groups depending on their nature. Special attention must be paid to the fact that, as is evident, all the handled entities were experimentally studied in an integrated way, not in isolated form. For instance, the measurements provided by sensors were processed and transmitted via fieldbus to an automation unit and a supervisory interface. The student is expected to experience a complete comprehension of the joint operation of the whole system, according to the Industry 4.0 concept.

Table 3. Elements handled by students during FPs using the FMS.

\begin{tabular}{cccccc}
\hline Software & Sensors & Actuators & Control Units & Supervisory Devices & Network Fieldbus \\
\hline TIA Portal & Presence & Electrical & PLC S7-300 and S7-1200 & Windows PC Runtime & PROFINET/Ethernet \\
SQL Manager & Position & Pneumatic & Servomotor driver & KTP 600 & PROFIBUS \\
Robot Studio & Encoder & Servomotor & Robot controller & & \\
\hline
\end{tabular}

\subsection{Considerations from Tutors}

Through a set of semistructured interviews, the opinions of the tutors were collected using a qualitative approach. The interviews took place once the FPs were completely finished, with the goal of registering the impressions of the tutors about the development and outcomes of the FPs. The semistructured interviews involved three open-ended questions to identify the advantages and drawbacks of using the FMS for FPs, as well as improvements that the educator planned to introduce in future projects. The most descriptive comments and reflections from tutors are shown in Table 4.

Table 4. Descriptive comments and reflections of tutors gathered through semistructured interviews.

\begin{tabular}{|c|c|}
\hline Advantages & Drawbacks \\
\hline $\begin{array}{l}\text { To my knowledge, this is the first time that the students } \\
\text { have managed equipment with a focus on the Industry } 4.0 \text {. } \\
\text { They have heard about the concept, the new industrial } \\
\text { revolution, but they have not really handled any laboratory } \\
\text { system compliant with it. This is imperative for them to } \\
\text { start to apprehend Industry } 4.0 \text { implications. }\end{array}$ & $\begin{array}{l}\text { Using proprietary software packages imposes } \\
\text { an important limit for the student because } \\
\text { he/she cannot follow programming or } \\
\text { configuring tasks at home: Their presence in the } \\
\text { laboratory is imposed. For the next projects, } \\
\text { the utilization of open source software and } \\
\text { hardware should be approached. }\end{array}$ \\
\hline $\begin{array}{l}\text { Each new project relies to a high degree on the previous } \\
\text { ones. For instance, the inclusion of the new station was } \\
\text { based on the automation and communication of the rest of } \\
\text { the stations. This is seen as a positive feature since students } \\
\text { do not learn isolated technologies but an integrated and } \\
\text { multidisciplinary environment. }\end{array}$ & $\begin{array}{l}\text { Tutoring a project in the Industry } 4.0 \text { is } \\
\text { an exciting task: However, the devoted time } \\
\text { and effort have been higher than in the case of } \\
\text { covering automation systems with more } \\
\text { traditional focuses. I have dedicated a lot of } \\
\text { time to studying the state of the art as well as } \\
\text { the Industry } 4.0 \text { requirements. }\end{array}$ \\
\hline
\end{tabular}


As a consequence of these collected perceptions, a set of initial considerations about the process of performing FPs around the FMS are expounded hereafter. To begin with, the main benefits found by the educators are now commented on:

- The handling of real industrial equipment constitutes one of the most significant advantages of the system. The FMS is composed of industrial components and is not specifically designed for educational purposes. Students learn and train using the same equipment and technologies that they will face in future professional environments. From the technical perspective, this feature facilitates the modification, addition, or reparation of components, since they use standardized signal ranges, communication protocols, and so forth.

- Accommodation of a number of emerging trends: The FMS can integrate different innovative approaches such as open source tools, virtual environments, and condition monitoring. This will be thoroughly commented on in the next subsection.

- The FMS does not suppose a disruptive scenario, since it is composed of well-known equipment such as PLCs and SCADA systems, as well as sensors and actuators. This feature contributes to facilitate the learning process of the educators, who in fact are also required to acquire deep expertise on innovative paradigms.

- Another benefit is the transversality of the FMS derived from the coexistence of different technologies common to engineering training such as ICT, informatics, and hardware skills, thus enabling the development of multidisciplinary projects.

- Applicability of the FMS for different degrees: As it has been commented on, the degree in Electronic Engineering and Automation is the most appropriate to deal with the FMS. However, other specializations that can also take advantage of the FMS capabilities are Electrical Engineering, Mechanical Engineering, and Chemical Engineering. In addition, out of the typically industrial engineering scope, other disciplines can be supported such as those devoted to telecommunications and informatics. They can be trained around the FMS with an orientation toward advanced networked communications and cyber-security issues, directly related to the Industry 4.0.

- Students become familiar with advanced concepts related to Industry 4.0, acquiring the basis to successfully develop their professional tasks within this challenging framework.

- Students are free to design the solutions that the FP implements, so their creative thinking and curiosity are expected to be stimulated. That is, the tutors guide the development but do not impose boundaries upon the incorporation of the ideas of the students. For instance, when designing the SCADA system, the student decided the layout, visual aspects, and other items according to his own criteria.

- $\quad$ All the FPs were agreed on by students and tutors instead of chosen from a list of available topics. This is considered to be a signal of the attraction that the FMS generates among the students.

- Different levels of autonomy were detected by the tutors. One of the main goals of the FPs is to promote the autonomy of students to learn by themselves and to solve troubles found in their path.

- Operational staff training could also be performed, for instance within a collaboration framework with industrial enterprises or vocational educational institutions. The integration of workers into an Industry 4.0 system is signaled as a significant challenge [35]: Even the term "operator 4.0" is gaining attention in the literature $[35,36]$.

As drawbacks, the following ones have been found:

- Utilization of proprietary technology both for software and hardware tools: For instance, this fact implies high costs in the acquisition of software licenses. It must be noted that, in order to solve this issue, some effort is being currently devoted to using open source hardware and software in the FMS. In addition, as is evident, the students acquire necessary knowledge and skills regardless of the particular software or hardware resources. 
- Previous expertise is required from students before the assignment of the FP. Aiming at maximizing the learning outcomes of the students, a minimum level of previous knowledge and skills are desirable before working with the FMS. The FMS is a complex and valuable equipment, so nowadays the criteria of the teachers is that students must have passed previous courses, mainly dealing with automation. Nonetheless, as it was stated in the second section, the FP offers an opportunity to reinforce or to acquire new knowledge and skills.

- Impossibility of performing a number of tasks outside of the physical laboratory: Students have to physically use the FMS for most of the FPs, so they need access to the laboratory and to stay inside during the required time. In other words, scarce tasks can be performed out of the laboratory, and therefore the FMS-based FPs are not suitable for those students that have some reason not to attend the laboratory (e.g., job, illness, childcare, or elder care).

- The tutoring task is scarcely considered within the teaching occupation. Despite the fact that tutors are commonly proud of encouraging the academic growth of FP students, the time and effort dedicated are not correctly valorized. The guidance of a FP is a time-consuming task, especially if it involves an experimental complex facility like the FMS. As was indicated in the second section, tutoring a FP is worth 0.25 European credits for the teacher. This is especially important when educators must face challenging topics such as the Industry 4.0 and related paradigms.

- Utilization of the FMS under project-based learning (PBL) methodology: Out of the FPs, within automation-related courses the FMS could be used to develop projects following the PBL technique so students have an active role and face a number of tasks that reinforce the contents provided during classes. Despite being an interesting application, deep expertise is required in order to avoid damage to the components of the FMS and of the students, though for advanced courses, a PBL approach could be conducted under the proper supervision of an educator.

- A small number of developed FPs around the FMS: Despite the fact that FPs have been successfully completed, the number of projects, and hence the number of involved students, is still small. In an exercise of self-criticism, this is considered to be a limitation of the presented work. Further analyses about pedagogical methodologies and the acquisition of Industry 4.0-related skills will be conducted when a larger amount is reached.

- Higher introduction of the Industry 4.0 paradigm in the engineering degrees: The challenges that this complex concept involves for educational institutions are still being discovered. It does not only require managing advanced equipment (hardware and software), but it implies a framework where a number of disciplines are orchestrated in an integrated manner. In this sense, the FMS has demonstrated itself to be a powerful platform in covering a number of scopes and is expected to incorporate new Industry 4.0-compliant features. Apart from this, institutions, particularly at the university level, need to update and adapt theoretical and practical content toward this new reality. This is in reference to both curricula and available equipment. Educators are also engaged in this process, since they have to modernize their own knowledge and skills. Even more, social aspects of the real deployment of Industry 4.0 must be tackled also in engineering degrees in order to generate successful engineers.

\subsection{Modern Manufacturing Trends Related to FMS}

Now that the developed FPs and associated outcomes have been expounded and discussed, the goal of this subsection is to provide an overview of the possibilities of the FMS in serving as a benchmark in a number of technological innovative trends. These possibilities highlight the versatility of the FMS and promote its utilization for a number of new FPs dealing with advanced concepts. This is a very valuable feature for didactic and educative systems. Some of the most recent trends in manufacturing and automation systems in the Industry 4.0 arena as well as their inclusion in the FMS via FPs are commented on thereafter. 
- Sustainability and environmental concerns achieve increasing attention for manufacturing systems [37]: Hence, various approaches can be carried out in the FMS in that sense. The monitoring of energy consumption in order to be considered in production planning or scheduling is an example.

- Condition monitoring and data acquisition are directly linked to advanced maintenance techniques such as prognostics and health management (PHM) schemes. The widespread deployment of various types of sensors makes it possible to achieve so-called smart monitoring [38]. In this sense, sensors to measure temperature and vibrations of the motors of the conveyor and the robotic arm will be added to provide information that will be used for PHM analysis. In a similar way, data-driven models and algorithms to improve decision-making processes require massive data acquisition and are aligned with big data analytics. These issues can also be handled using the FMS as a benchmark to deploy a number of sensors and process the gathered data.

- Cyber-security is a paramount issue in modern automation networks, so its efficient management must be performed by engineering students [39]. Protections in the SCADA system will be the main issue to handle in the FMS.

- Open source hardware and software resources are receiving efforts in the automation and monitoring scopes [40-42]. Indeed, these resources are being signaled as key accelerators for the industry adoption of the IoT [43]. Supervisory systems and microcontrollers of this nature can be accommodated in the FMS through FPs to evaluate their functionalities. Even more, students can use their own devices, which constitutes a modern trend termed bring your own device (BYOD), aiming to encourage their motivation. Particularly, inexpensive open source hardware platforms such as the Arduino microcontroller or the Raspberry Pi microprocessor can be applied under such a movement.

- Online remote laboratories constitute a useful resource for educational purposes [44] and are also under the umbrella of the Industry 4.0 [45]. Indeed, the above-mentioned open source technology facilitates the deployment of remote laboratories [46], so their application to the FMS could promote its utilization as an online laboratory.

- Virtualization of manufacturing processes through augmented or virtual reality is an emergent trend $[37,47,48]$. For instance, the design of a 3D virtual world to provide immersive experiences within the automated processes will enrich the motivation and skills of students.

- Radio frequency identification (RFID) technology is a key technology for Industry 4.0 and IIoT scenarios [49]. Its integration, through proprietary or open source means, in the FMS will enable traceability and continuous tracking purposes.

- Additive manufacturing or 3D printing is considered to be one of the enabling technologies of Industry 4.0 [19]. The 3D Cartesian robot that is under development will allow for introducing this technology in the FMS.

- Other developments such as those related to CM possibilities [50] or advanced human-machine interactions [31] can also be accommodated in the FMS.

\section{Conclusions}

This paper presented the utilization of an industrial experimental FMS as a didactic platform in the context of Industry 4.0, enabling the development of FPs in engineering degrees. The utilization of the FMS for this purpose started in the academic year 2011-2012 and still remains active, with a number of FPs being carried out nowadays. A total number of 12 projects have concluded up to the present date. As a sample, four of them were expounded, namely those related to automation, robotics, supervisory systems, and data management tasks.

The academic outcomes achieved by the students illustrate a fruitful utilization of the FMS. A set of initial considerations from the tutors of the FPs were also provided in order to offer useful insights for other educators and researchers. 
The FMS provides a versatile environment since it integrates diverse technologies as well as hardware and software entities among which students can train a multiplicity of skills aligned with Industry 4.0 principles, empowering the education of students in such a challenging modern paradigm. Nevertheless, there is still a long way to go for evaluating the benefits of using the FMS as well as the acquisition of Industry 4.0-related skills through a larger amount of FPs.

Future guidelines include the development of FPs as well as PhD theses considering the innovative trends commented on in Section 4.3, those being the open source technology integration currently approached. Moreover, a survey to collect the students' opinions is being designed and applied. Additionally, in-depth qualitative analysis will be performed in further works. The results will be analyzed and will serve as constructive feedback about the learning experience around the FMS.

Author Contributions: Conceptualization, I.G. and A.J.C.; Investigation, I.G. and A.J.C.; Methodology, I.G. and A.J.C.; Resources, I.G. and A.J.C.; Validation, I.G. and A.J.C.; Writing-Original Draft Preparation, I.G. and A.J.C.; Writing-Review \& Editing, I.G. and A.J.C.

Funding: This research received no external funding.

Acknowledgments: The authors are grateful to the students who developed the projects under their tutoring. In addition, the authors wish to thank the anonymous reviewers for their valuable suggestions that allowed for improving this article.

Conflicts of Interest: The authors declare no conflict of interest.

\section{Abbreviations}

The following abbreviations were used in this manuscript:

\begin{tabular}{ll} 
BYOD & Bring your own device \\
CM & Cloud manufacturing \\
DM & Dissertation mark \\
EHEA & European Higher Education Area \\
ERP & Enterprise resource planning \\
ICPS & Industrial cyber-physical systems \\
ICT & Information and communication technology \\
IE & Industrial Ethernet \\
IES & Industrial Engineering School \\
IIoT & Industrial Internet of Things \\
FM & Final mark \\
FMS & Flexible manufacturing system \\
FP & Final project \\
LAN & Local area network \\
LF & Learning factory \\
LMS & Learning management system \\
MES & Manufacturing execution systems \\
PBL & Project-based learning \\
PHM & Prognostics and health management \\
PLC & Programmable logic controller \\
PROFIBUS & Process Fieldbus \\
RAPID & Robotics application programming interactive dialogue \\
RFID & Radio frequency identification \\
RM & Report mark \\
SCADA & Supervisory control and data acquisition \\
SQL & Structured Query Language \\
UEX & University of Extremadura \\
VB & Visual Basic \\
& \\
\hline
\end{tabular}




\section{References}

1. Ismail, A.; Kastner, W. A middleware architecture for vertical integration. In Proceedings of the 1st International Workshop on Cyber Physical Production Systems (CPPS), Vienna, Austria, 12 April 2016. [CrossRef]

2. Iglesias-Urkia, M.; Orive, A.; Barcelo, M.; Moran, A.; Bilbao, J.; Urbieta, A. Towards a lightweight protocol for Industry 4.0: An implementation based benchmark. In Proceedings of the IEEE International Workshop of Electronics, Control, Measurement, Signals and Their Application to Mechatronics, San Sebastian, Spain, 24-26 May 2017. [CrossRef]

3. Cohen, Y.; Faccio, M.; Gabriele, F.; Mora, C.; Pilati, F. Assembly system configuration through Industry 4.0 principles: The expected change in the actual paradigms. IFAC-PapersOnLine 2017, 50, 14958-14963. [CrossRef]

4. $\quad$ Müller, J.M.; Voigt, K.-I. Sustainable Industrial Value Creation in SMEs: A Comparison between Industry 4.0 and Made in China 2025. Int. J. Precis. Eng. Manuf.-Green Technol. 2018, 5, 659-670. [CrossRef]

5. Ji, X.; He, G.; Xu, J.; Guo, Y. Study on the mode of intelligent chemical industry based on cyber-physical system and its implementation. Adv. Eng. Softw. 2016, 99, 18-26. [CrossRef]

6. Redutskiy, Y. Conceptualization of smart solutions in oil and gas industry. Procedia Comput. Sci. 2017, 109, 745-753. [CrossRef]

7. González, I.; Calderón, A.J.; Figueiredo, J.; Sousa, J.M.C. Design of an educational platform for automation and supervision under the Industry 4.0 framework. In Proceedings of the 12th International Technology, Education and Development Conference (INTED), Valencia, Spain, 5-7 March 2018.

8. Müller, J.M.; Kiel, D.; Voigt, K.-I. What Drives the Implementation of Industry 4.0? The Role of Opportunities and Challenges in the Context of Sustainability. Sustainability 2018, 10, 247. [CrossRef]

9. Benešová, A.; Tupa, J. Requirements for Education and Qualification of People in Industry 4.0. Procedia Manuf. 2017, 11, 2195-2202. [CrossRef]

10. Simons, S.; Abé, P.; Neser, S. Learning in the AutFab-The fully automated Industrie 4.0 learning factory of the University of Applied Sciences Darmstadt. Procedia Manuf. 2017, 9, 81-88. [CrossRef]

11. Prinz, C.; Morlock, F.; Freith, S.; Kreggenfeld, N.; Kreimeier, D.; Kuhlenkötter, B. Learning Factory modules for smart factories in Industrie 4.0. Procedia CIRP 2016, 54, 113-118. [CrossRef]

12. Madsen, O.; Moller, C. The AAU Smart Production Laboratory for teaching and research in emerging digital manufacturing technologies. Procedia Manuf. 2017, 9, 106-112. [CrossRef]

13. Mourtzis, D.; Vlachou, E.; Dimitrakopoulos, G.; Zogopoulos, V. Cyber- Physical Systems and Education 4.0-The Teaching Factory 4.0 Concept. Procedia Manuf. 2018, 23, 129-134. [CrossRef]

14. Ramirez-Mendoza, R.A.; Morales-Menendez, R.; Iqbal, H.; Parra-Saldivar, R. Engineering Education 4.0-Proposal for a new Curricula. In Proceedings of the IEEE Global Engineering Education Conference (EDUCON), Canary Islands, Spain, 17-20 April 2018. [CrossRef]

15. Rojko, A.; Hercog, D.; Jezernik, K. E-training in mechatronics using innovative remote laboratory. Math. Comput. Simul. 2011, 82, 508-516. [CrossRef]

16. Villa-López, F.H.; García-Guzmán, J.; Vélez Enríquez, J.; Leal-Ortíz, S.; Ramírez-Ramírez, A. Electropneumatic system for industrial automation: A remote experiment within a web-based learning environment. Procedia Technol. 2013, 7, 198-207. [CrossRef]

17. Balid, W.; Abdulwahed, M. The Impact of Different Pre-Lab Preparation Modes on Embedded Systems Hands-on Lab. In Proceedings of the 9th Annual American Society for Engineering Education (ASEE) Global Colloquium on Engineering Education, Budapest, Hungary, 12-15 October 2009.

18. Calderón Godoy, A.J.; González Pérez, I. Integration of Sensor and Actuator Networks and the SCADA System to Promote the Migration of the Legacy Flexible Manufacturing System towards the Industry 4.0 Concept. J. Sens. Actuator Netw. 2018, 7, 23. [CrossRef]

19. Bortolini, M.; Galizia, F.G.; Mora, C. Reconfigurable manufacturing systems: Literature review and research trend. J. Manuf. Syst. 2018, 49, 93-106. [CrossRef]

20. Girbea, A.; Suciu, C.; Nechifor, S.; Sisak, F. Design and implementation of a service-oriented architecture for the optimization of industrial applications. IEEE Trans. Ind. Inform. 2014, 10, 185-196. [CrossRef]

21. Kammoun, M.A.; Ezzeddine, W.; Rezg, N.; Achour, Z. FMS Scheduling under Availability Constraint with Supervisor Based on Timed Petri Nets. Appl. Sci. 2017, 7, 399. [CrossRef] 
22. Scholze, S.; Barata, J.; Stokic, D. Holistic Context-Sensitivity for Run-Time Optimization of Flexible Manufacturing Systems. Sensors 2017, 17, 455. [CrossRef]

23. Priore, P.; Ponte, B.; Puente, J.; Gómez, A. Learning-based scheduling of flexible manufacturing systems using ensemble methods. Comput. Ind. Eng. 2018, 126, 282-291. [CrossRef]

24. García, M.V.; Irisarri, E.; Pérez, F.; Estévez, E.; Marcos, M. OPC-UA Communications Integration using a CPPS architecture. In Proceedings of the IEEE Ecuador Technical Chapters Meeting (ETCM), Guayaquil, Ecuador, 12-14 October 2016. [CrossRef]

25. Pisching, M.A.; Pessoa, M.A.O.; Junqueira, F.; Filho, D.J.; Miyagi, P.E. An architecture based on RAMI 4.0 to discover equipment to process operations required by products. Comput. Ind. Eng. 2018, 125, 574-591. [CrossRef]

26. Prada, M.A.; Fuertes, J.J.; Alonso, S.; García, S.; Domínguez, M. Challenges and solutions in remote laboratories. Application to a remote laboratory of an electro-pneumatic classification cell. Comput. Educ. 2015, 85, 180-190. [CrossRef]

27. Reynard, S.; Gomis-Bellmunt, O.; Sudriá-Andreu, A.; Boix-Aragonés, O.; Benítez-Pina, I. Flexible manufacturing cell SCADA system for educational purposes. Comput. Appl. Eng. Educ. 2008, 16, 21-30. [CrossRef]

28. Yabanova, I.; Taskin, S.; Ekiz, H. Development of remote monitoring and control system for mechatronics engineering practice: The case of flexible manufacturing system. Int. J. Elec. Eng. Educ. 2015, 52, 264-275. [CrossRef]

29. Hincapié, M.; Ramírez, M.J.; Valenzuela, A.; Valdez, J.A. Mixing real and virtual components in automated manufacturing systems using PLM tools. Int. J. Interact. Des. Manuf. 2014, 8, 209-230. [CrossRef]

30. Toivonen, V.; Lanz, M.; Nylund, H.; Nieminen, H. The FMS Training Center-A versatile learning environment for engineering education. Procedia Manuf. 2018, 23, 135-140. [CrossRef]

31. Pacaux-Lemoine, M.-P.; Trentesaux, D.; Zambrano, G.; Millot, P. Designing intelligent manufacturing systems through Human-Machine Cooperation principles: A human-centered approach. Comput. Ind. Eng. 2017, 111, 581-595. [CrossRef]

32. Tisch, M.; Hertle, C.; Abele, E.; Metternich, J.; Tenberg, R. Learning factory design: A competency-oriented approach integrating three design levels. Int. J. Comput. Integr. Manuf. 2016, 29, 1355-1375. [CrossRef]

33. Webpage of the Industrial Engineering School of the University of Extremadura. Available online: eii.unex.es (accessed on 15 September 2018).

34. SMC Webpage. Available online: https://www.smc.eu/portal_ssl/WebContent/main/index_restyling.jsp? lang=en\&ctry=EU\&is_main=yes\&dfl_locale=yes (accessed on 10 September 2018).

35. Ruppert, T.; Jaskó, S.; Holczinger, T.; Abonyi, J. Enabling Technologies for Operator 4.0: A Survey. Appl. Sci. 2018, 8, 1650. [CrossRef]

36. Zolotová, I.; Papcun, P.; Kajáti, E.; Miskuf, M.; Mocnej, J. Smart and Cognitive Solutions for Operator 4.0: Laboratory H-CPPS Case Studies. Comput. Ind. Eng. 2018, in press. [CrossRef]

37. Esmaeilian, B.; Behdad, S.; Wang, B. The evolution and future of manufacturing: A review. J. Manuf. Syst. 2016, 39, 79-100. [CrossRef]

38. Zhong, R.Y.; Xu, X.; Klotz, E.; Newman, S.T. Intelligent Manufacturing in the Context of Industry 4.0: A Review. Engineering 2017, 3, 616-630. [CrossRef]

39. Domínguez, M.; Prada, M.A.; Reguera, P.; Fuertes, J.J.; Alonso, S.; Morán, A. Cybersecurity training in control systems using real equipment. IFAC-PapersOnLine 2017, 50, 12179-12184. [CrossRef]

40. Calderón, A.J.; González, I.; Calderón, M.; Segura, F.; Andújar, J.M. A New, Scalable and Low Cost Multi-Channel Monitoring System for Polymer Electrolyte Fuel Cells. Sensors 2016, 16, 349. [CrossRef] [PubMed]

41. González, I.; Calderón, A.J.; Mejías, A.; Andújar, J.M. Novel networked remote laboratory architecture for open connectivity based on PLC-OPC-LabVIEW-EJS integration. Application to remote fuzzy control and sensors data acquisition. Sensors 2016, 16, 1822. [CrossRef]

42. González, I.; Calderón, A.J.; Andújar, J.M. Novel Remote Monitoring Platform for RES-Hydrogen based Smart Microgrid. Energy Conv. Manag 2017, 148, 489-505. [CrossRef]

43. Martinez, B.; Vilajosana, X.; Kim, I.H.; Zhou, J.; Tuset-Peiró, P.; Xhafa, A.; Poissonnier, D.; Lu, X. I3Mote: An Open Development Platform for the Intelligent Industrial Internet. Sensors 2017, 17, 986. [CrossRef] [PubMed] 
44. Viegas, C.; Pavani, A.; Lima, N.; Marques, A.; Pozzo, I.; Dobboletta, E.; Atencia, V.; Barreto, D.; Calliari, F.; Fidalgo, A.; et al. Impact of a remote lab on teaching practices and student learning. Comput. Educ. 2018, 126, 201-216. [CrossRef]

45. Grodotzki, J.; Ortelt, T.R.; Tekkaya, A.E. Remote and Virtual Labs for Engineering Education 4.0. Procedia Manuf. 2018, 26, 1349-1360. [CrossRef]

46. Mejías, A.; Reyes, M.; Márquez, M.A.; Calderón, A.J.; González, I.; Andújar, J.M. Easy handling of sensors and actuators over TCP/IP Networks by Open Source Hardware/Software. Sensors 2017, 17, 94. [CrossRef] [PubMed]

47. Bruzzone, A.G.; Longo, F. 3D simulation as training tool in container terminals: The TRAINPORTS simulator. J. Manuf. Syst. 2013, 32, 85-98. [CrossRef]

48. Scurati, G.W.; Gattullo, M.; Fiorentino, M.; Ferrise, F.; Bordegoni, M.; Uva, A.E. Converting maintenance actions into standard symbols for Augmented Reality applications in Industry 4.0. Comput. Ind. 2018, 98, 68-79. [CrossRef]

49. González, I.; Calderón, A.J.; Barragán, A.J.; Andújar, J.M. Integration of Sensors, Controllers and Instruments Using a Novel OPC Architecture. Sensors 2017, 17, 1512. [CrossRef]

50. Fisher, O.; Watson, N.; Porcu, L.; Bacon, D.; Rigley, M.; Gomes, R.L. Cloud manufacturing as a sustainable process manufacturing route. J. Manuf. Syst. 2018, 47, 53-68. [CrossRef]

(c) 2018 by the authors. Licensee MDPI, Basel, Switzerland. This article is an open access article distributed under the terms and conditions of the Creative Commons Attribution (CC BY) license (http:/ / creativecommons.org/licenses/by/4.0/). 